\title{
Subject Enhancement: Report on an Experiment
}

\section{Gunnar Knutson}

This report describes an experiment in subject enhancement conducted at an academic research library. Subjects and contents notes were added to online catalog records for a group of previously uncirculated social science essay collections, and circulation was monitored over one academic year. A control group, plus a third group with added contents notes but no extra subjects, were also monitored. Results showed an improvement in recorded use for the subject-enhanced titles, but not for titles that only had added contents notes. The effects of browsing, keyword searching, and OPAC display are discussed, and suggestions made for further research in this area.

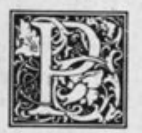

roviding better subject access to collections is an important issue to research libraries. This report describes a oneyear experiment designed to determine whether adding a substantial number of controlled vocabulary subject headings will raise circulation rates. The effects of added contents notes, keyword searching, and browsing are also examined. Benefits of increased subject access are presented and discussed, and further research in related areas is suggested.

This project addresses two basic questions. First, can changes in subject cataloging policy improve the likelihood that some unused or little used materials in research collections will circulate? Second, is there a particular type of improvement that can be demonstrated as suitable for this purpose?

One way to view the overall problem is to consider whether the lack of recorded use of large parts of a research collection may reflect deficiencies in the current level of subject cataloging. Do research libraries really contain many thousands of books which do not circulate simply because patrons do not have good access to their subject matter, or is the frequency of book circulation basi- cally unrelated to the catalog record?

These are questions which confront librarians concerned with improving access while working within budget constraints. The online catalog makes it possible to consider a wide range of potential improvements, yet too little is known of the effects of such changes. They may be only "improved means to an unimproved end," as Thoreau once described technological progress. Today we might ask if changes to the catalog record will actually result in increased use of library materials, or whether, despite better bibliographic access, users will still choose more or less the same titles and leave the same large percentage of the collection uncirculated.

\section{LITERATURE REVIEW}

Insufficient subject access in standard cataloging has become almost a truism in the critical literature. The average number of Library of Congress subject headings on OCLC MARC records has been estimated at about 1.4, though this varies somewhat by classification and may have increased in recent years. ${ }^{1}$ (The author noted an average of about 2.6 subjects per record for social science titles in the current study, compared to 
1.8 for similar titles in the above mentioned study.) James R. Dwyer summarized the problem by stating that "our clients are requesting not just more and better subject access, but a deeper analysis of the contents of library materials. ${ }^{2}$

Two books appearing in the late 1970 s-only one of which dealt directly with subject access-serve as contrasting viewpoints on the overall question of the relationship between the catalog and book use. Use of Library Materials (often referred to as the Pittsburgh study) analyzed automated circulation data to show how, over a long period of time, a large portion of a research collection is unlikely to have any recorded use. ${ }^{3}$ Though much of the data was consistent with other studies, the report generated a great deal of controversy for its methodology and conclusions. Some critics argued that the study showed little understanding of the special nature of research collections, and they defended low recorded use as unimportant to the mission of academic research.

We know that in large academic libraries many books seldom, if ever, circulate. We suspect that this is partly due to inadequate subject access.

The closing chapter of the Pittsburgh study acknowledges that cataloging improvements might affect circulation rates, but this statement is peripheral to the overall message that "only $56 \%$ to $60 \%$ of the books and monographs added to the collection in any one year ever circulate." study is that nonuse of books is more a problem of book selection than of cataloging.

Pauline Atherton presented a contrasting viewpoint in the Books are for Use report. That report saw nonuse of books as primarily a subject catalog failure: "Our investment in books is partially wasted and underused if access is only available to those who come to the library catalog to search for known items. ${ }^{\prime 5}$ Atherton's approach was to augment a test file of MARC records with subject descriptors taken from the books, providing greater online accessibility through free-text searching. The experiment reported encouraging progress in improving subject access, though it was not designed to measure changes in circulation patterns in research collections. A recent project at the Australian Defence Force Academy Library, using the same technique, had similar findings of better retrieval but also does not report on how book use was affected. ${ }^{6}$

Other research demonstrates the difficulty of linking book use to the fullness of the bibliographic record. At times it appears that the standard catalog record is all but irrelevant, as in William Aguilar's experiment. ${ }^{7}$ Aguilar removed catalog cards for a sample of books in a small public library and found that circulation was not affected. Margaret Ann Thomas Taylor ${ }^{8}$ found no consistent positive correlation between depth of existing cataloging and book use in a larger public library, while similar results were reported in two different university settings. 9,10

The contradictions of this situation can be appreciated by a summary of the various research. We know that in large academic libraries many books seldom, if ever, circulate. We suspect that this is partly due to inadequate subject access, yet the presence of more LC subjects seemingly has no link to higher circulation. A different approach to subject cataloging may be necessary, but too little is known of what such changes should be, or of probable user reaction. Also, as Carol A. Mandel and Judith Herschman point out, libraries have an "enormous investment" in the traditional LC subject system. ${ }^{11}$ Libraries are not likely simply to abandon LC subjects as a means of access. Part of the challenge facing research libraries is to find ways to modify current subject cataloging practices so that materials are more accessible to users.

In a previous research report involv- 
ing statistical tests of average numbers of subjects compared to circulations, the author concluded "that merely increasing the number of LC subject headings may have little or no measurable effect on book retrieval and use." This finding was qualified by the acknowledged possibility that "an incremental increase in subject headings, such as from one or two up to three or four, is not significantly associated with circulation, but that a very large increase up to perhaps ten or more-which would also allow access to subsets of information in monographs-may show an association with use figures. " 12

William Carl Highfill earlier demonstrated that "those books which have been assigned a greater number of subject headings have a greater chance of being selected by catalog users during subject searches." ${ }^{13}$ Although that experiment did not measure book circulation, it is a logical assumption that a number of the subjects selected in catalog searches will lead to book uses. Highfill suggested that "to increase the retrieval potential of the subject catalog, the number of access points per document should be increased.",14

All of these studies argue the importance of attempting to demonstrate an actual increase in collection use based on a new approach to subject cataloging. An important point is that, in current cataloging, marginal differences in the number of controlled subjects per record most often reflect the attempt of a cataloging agency to provide standard levels of access. This may be one, two, or several subjects-however many are needed to provide a general subject summary of the contents of a work.

It is not the practice of the Library of Congress or of most other libraries to provide enough subjects for chapter level access to most works. The very real economic consideration of a known cost and the not well known benefits of increasing the level of subject analysis prevents libraries from making a sharp break with tradition in subject cataloging.

The practice of summarizing subject content rather than trying to describe each part may be why the few attempts to show a positive correlation between numbers of subjects and use of books have proved futile. If, roughly speaking, the current system provides an adequate general description of subject matter, there should be little relative difference in use of books whether they have one or several subjects. By going to the chapter level, however, it may be possible both to improve retrieval and to increase the likelihood of circulation.

Keyword searching is one way of potentially getting to more specific subject matter within a book. As noted above, Atherton and subsequent researchers have demonstrated that users can be more successful in matching terms through keyword searching than by traditional controlled vocabulary subject searches. However, keyword searching is not universally available on library catalogs, nor is it without limitations. Such searches may retrieve a mass of information that is difficult to sort through, and some keywords will not reflect the true subject matter being sought. Response time may also be slow. Keyword searching is an important advance but is not the only method to consider for catalog improvements.

Several years ago Mandel concluded a review on methods of improving subject access by asking, "Should we enhance the MARC record to improve subject access?" and stated, "We won't know until we try." ${ }^{15}$ She noted that LC was not likely to alter its cataloging policies without good reason, and that "the hard research evidence needed to make such a case for enriched MARC records does not yet exist." ${ }^{16}$ Recent research such as the Australian experiment mentioned above, Karen Markey and Karen Calhoun's demonstration of the value of adding content-rich terms to records, ${ }^{17}$ and the OCLC test database with added tables of contents and abstracts, ${ }^{18}$ address some of the possibilities.

One of the options listed by Mandel was additional LCSH controlled vocabulary indexing (" the most labor-intensive option"'). ${ }^{19}$ The current experiment is an 
attempt to implement a version of this approach on a subset of materials in one academic library.

\section{METHODOLOGY}

The study took place at the Main Library of the University of Illinois at Chicago (UIC). This library holds over 600,000 titles in open stacks. Principal access is provided by a NOTIS-based online public catalog (LUIS). In addition, circulation information for this and other Illinois libraries is available on LCS terminals. (In mid-1988 the LCS catalog was expanded to provide a full bibliographic record via Illinet Online (IO).) The card catalog at the study library was still in place during the experiment but had been frozen since the end of 1985 . (The online LUIS catalog has records for all books cataloged since 1977 , plus most earlier titles. An estimated $10 \%$ of the collection was not converted as of the 1988/89 academic year.)

At the time of the study, patron use was heavily weighted toward LUIS because it was the most current catalog, the easiest to use, and was available on many terminals throughout the library as well as through the university's extensive computer network. The card catalog no longer had records for current acquisitions and was not heavily used, while the LCS/IO system was used primarily to check circulation data and for resource sharing.

The author decided to conduct the experiment through the LUIS catalog, based on circulation of books in the regular collection. A separate data file might have been used instead, but that would not have addressed the question of whether subject enhancements added to a large existing catalog could have a positive effect on book use.

Circulation was chosen as the measure of use. Larry Hardesty notes that "recorded circulation is a good indicator of the total use of books., ${ }^{, 20}$ In-house use may vary somewhat, but it follows the same general pattern as recorded circulation.

Selecting a suitable group of books to enhance involved three stages. The au- thor chose to concentrate on a single area-the Library of Congress H classification, which covers a broad range of social science material. In order to learn more about circulation patterns and their effect on this experiment, the author examined a sample of UIC social science holdings and compared the findings to data from the Pittsburgh study on book use. Because the current study focused only on the high-use social science classification and did not include multiple copy or volume items, while the Pittsburgh study reported total circulation, only a general comparison could be made.

The comprehensive Pittsburgh data showed that books were most likely to circulate for the first time within the first two years after being added to the collection. Beginning in the third year after cataloging, recorded first-time use dropped sharply and steadily. After six years, about $60 \%$ of the titles had one or more recorded circulations, and this figure increased only at a very gradual rate in subsequent years. ${ }^{21}$

A sample list of 372 titles added to the UIC Library's social science collection in 1981 was available from a previous project. After six years, 334 of the titles could be accounted for by a shelf check or were currently checked out. Of these, 244 $(73 \%)$ had circulated at least once. Most of the books had been checked out initially in the first or second calendar year in the collection. Although the use rate was considerably higher than the overall figure in the Pittsburgh study, there was a significant group of uncirculated items even in this high-use area. The author examined these ninety uncirculated books and considered them for subject enhancement potential.

Examination of the uncirculated 1981 social science titles was revealing and helped shape the experiment. As a group, these books were not good candidates for subject enhancement. Too many were on narrow topics that were well covered by their existing subjects. The passage of six years had left a disproportionate number of highly specialized titles that seemed unlikely to circu- 
late often regardless of the catalog record. There were books whose use might well have been promoted by added subjects, but they were too few to form the basis of a study without taking a very large sample of books this old.

Previously circulated books could have been used, but this would introduce an unwanted complication because it is obvious that certain popular titles will be in almost constant use regardless of the catalog record.

Adding more subjects when cataloging new books was another possibility, but this seemed undesirable for several reasons. A number of works are special ordered for patrons and thus circulate for the first time without the influence of the catalog record. Newly cataloged titles also appear on monthly book lists sent to all university departments as well as to interested faculty. These lists are posted near the circulation desk, where dust jackets for some new books are also displayed. Another problem is that library staff may request a new book as it is being processed. It seemed best to eliminate as many of these extraneous influences on book use as possible.

Based on what was learned from this preliminary work, the author concluded that the research sample should be chosen from books that had been in the collection for two or three years, thus increasing the likelihood that patrons would use the catalog to locate a title. Using 1986 as the base year simplified the process because new subjects only had to be added to the online catalog (the card catalog having been closed in 1985). Accordingly, a 685-record sample of 1986 social science acquisitions was taken. About $57 \%$ of the books which could be accounted for (in December 1987) had circulated at least once since being cataloged.

Although this process provided a wider range of material, the books in the sample which had not circulated $(43 \%)$ still presented a problem for subject enhancement. Compilations of essays and conference papers within this group were clearly most suitable for the final experiment. While some single-author monographs might also have been suitable, many appeared to be completely described by the general subjects they already had. Eliminating such books would have required subjective judgments that would have biased the experiment. Therefore, the project was limited to essay collections and conference proceedings that had discrete parts to which subject headings could be assigned. Every uncirculated book in these categories could be treated similarly. The author assumed that this would provide a fair test of materials that would be good subject enhancement candidates in any library. Whether other kinds of books would provide similar results was too broad a question to address in this experiment.

The author surveyed new books lists to locate all such essay compilations added to the $\mathrm{H}$ classification in 1986 , made printouts of the catalog records for appropriate titles, and examined each book. Shelf searches, done in the spring of 1988 , showed that $61 \%$ of the essay and conference paper collections added in 1986 had circulated at least once. The passage of several months between the survey of general social science books and these compilations would have raised the use rate somewhat, so the figures of $57 \%$ use for $\mathrm{H}$ class as a whole and $61 \%$ use for essay collections after two-plus years in the library are actually quite comparable. This finding-that essay collections did not have a distinct circulation pattern-increased the likelihood that the results of the experiment could have implications for those singleauthor monographs suitable for subject enhancement.

Subject additions to the catalog records were made at the end of the 1988 summer quarter. At that point there were 291 uncirculated compilations of $\mathrm{H}$ classification essays and conference papers which had been cataloged during 1986 and were thus eligible for the project. Some of these records served as a control group, while others received added subjects and a full contents note.

A contents note was added to any record receiving added subjects so that a 
user might see that a particular subject often applied only to one or two essays within the book. However, because of the availability of keyword searching in the online public catalog, the presence or absence of contents notes was a potentially confounding factor in interpreting test results. If the group with more subjects circulated more often than the control, this might be linked to keyword searching rather than, or in addition to, the added subjects. Therefore, the 291 records were divided into three groups: an enhance group, with added subjects and contents notes; a control group, with no added subjects or contents notes; and a third group, with no added subjects but with full contents notes. This division would provide some measure of the relative importance of the added subjects as opposed to contents notes in the subsequent use of the books.

Because circulation rates within the $\mathrm{H}$ subclass areas varied, the records were put in call number order and systematically assigned to one of the three groups to assure that there was no concentration of records within an area with a potentially higher or lower use rate. An order of one enhance record, followed by one control record, followed by one contents-note-only record, was chosen by lot and followed throughout.

Because these titles represented the entire range of uncirculated books of this type, they were not always ideal for subject enhancement. Some problems encountered involved conference proceedings with large numbers of papers on esoteric topics that do not have exact matches with LC subject terms and essay collections with little range of subject matter. These factors, plus the varying number of subjects already on the records, precluded giving a standard number of added subjects to each record. Nevertheless, every third title received as many new subjects as were practical to assign.

Before the enhancements, the records had an average of about 2.5 LC subjects with a range from one to six. They received an average of five new subjects, giving them an average of 7.5 subjects with a new range of from three to thirteen. This represented an average increase in subject headings of about $200 \%$.

Despite the fact that these were all collections of essays, only thirty-four of the 291 original records had contents notes. In most cases it was necessary to add such notes to the enhance group and the contents note group. In a few cases the contents notes were excessively long, and the author shortened them by abbreviating forenames, leaving off second and third authors, or by limiting them to the first twenty essay titles. In no case was any information justifying an added subject entry left off the contents note.

Most of the work was done during evenings or on weekends when the library was closed so that the books would be off the shelves for as little time as possible (though the data tally did not begin until all preparations were complete). The department's Principal Cataloger checked the initial enhancements to verify that the subjects were appropriate to add within the framework of the project.

Final work was completed before the start of the 1988 fall quarter. Circulation was monitored twice a month on the online LCS circulation system over the course of one academic year, from September 12, 1988, through September 10, 1989. In addition, during the middle of each quarter, the author did a shelf check to identify any missing books or miscellaneous problems. At the conclusion of the project a final shelf check was made, and a printout of circulation figures for the classification over the preceding year was obtained from the LCS office to verify all data.

The combination of regular LCS searching plus the final printouts made it possible to distinguish local from nonlocal uses and to distinguish renewals from separate circulation transactions, thus providing more meaningful data for analysis. Precise data were important because only the local online catalog (LUIS) records had been modified and 
because undifferentiated circulation data can be misleading. These practices also made it possible to chart circulation patterns over the academic year. There were still some minor difficulties, however, as discussed in the findings section below.

The main limitation of the experiment was that circulation transactions could not be linked to any prior searching by a specific user at a specific terminal, so that transaction logs might in turn be examined to see what search terms had been used. Given the small number of expected circulations spread over an entire year, it was also impractical to administer a user survey. A survey form might have been inserted in the books, but there seemed no way to assure that response would be meaningfully high, and the presence of an obtrusive form could actually have discouraged some use. Confidentiality issues precluded using circulation records to contact patrons for interviews.

Aware of these limitations, the author did not assume that all the circulations resulted from online subject searches, but given the size of the library and the heavy use of the online public catalog (nearly 3,900,000 separate search transactions over the academic year), the influence of the catalog record should have been considerable. Known-item searches and browsing must have accounted for a portion of the local circulations, but this should have affected all three groups equally.

The null hypothesis of the study was that circulation frequency is independent of variations in the catalog record (namely, the added subject headings and contents notes). Based on earlier research, it seemed unlikely that a pattern of more use for the enhanced records would be found.

\section{FINDINGS}

During the year, fifty-seven (19.6\%) of the 291 titles circulated at least once. There were ninety-eight total circulation transactions for the experimental group, including renewals and external use. Two problems arose, both in the con- tents note group. One of the books disappeared between the preparations stage and the beginning of the test period and had to be removed from the final calculations. Also, despite all the precautions taken, one circulation could not be positively identified as local or nonlocal. Because of its brevity, the circulation was counted as local, but this was not absolutely certain.

\section{Based on earlier research, it seemed unlikely that a pattern of more use for the records would be found.}

Use figures were analyzed in several ways, including the number of titles circulating locally for the first time, the number of separate local circulations (excluding renewals), the number of total local circulations, and the total number of circulations including interlibrary loan and renewals. Each method gives a somewhat different perspective on book use.

Figures 1 and 2 provide an overview of the year's online public catalog use and the circulation of the experimental books. By comparing the two figures one can see that, in general, circulation of books in the experimental groups follows high and low use periods of the catalog, which in turn closely mirrors the academic year. Public catalog use rises to well over 100,000 transactions per week each quarter, peaks late in the quarter, and then drops sharply around finals. Summer has about half the online cata$\log$ activity as other quarters.

Because none of the sample books had a prior circulation history, the experiment provided a ready measure of first time use. The Pittsburgh study demonstrated that such use diminishes with length of time in the collection, and because the titles in the current study were uncirculated after being in the collection for more than two years (on average), the expected circulation rate was not 


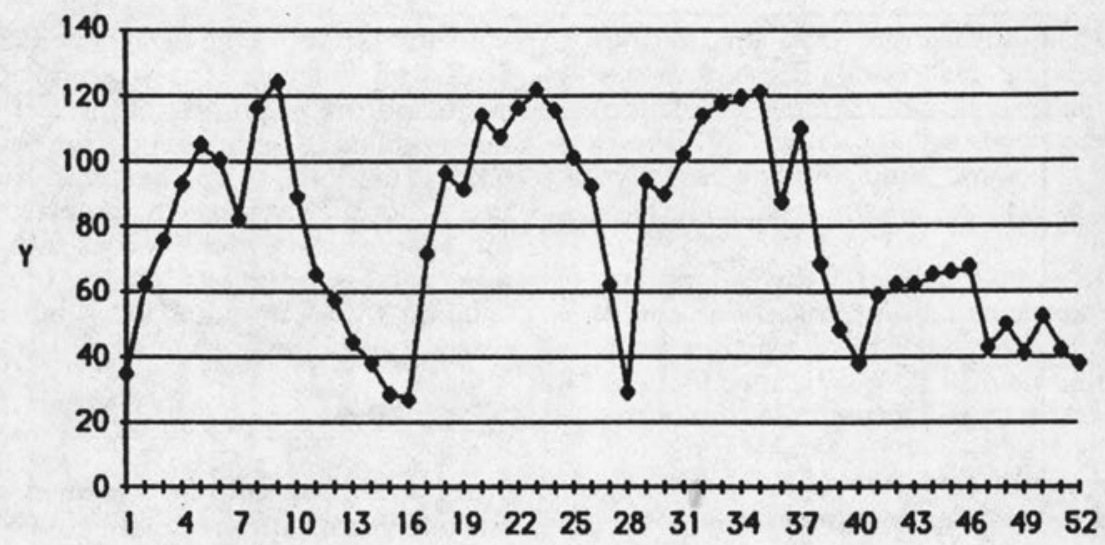

$\mathbf{X}$

$X$ axis $=$ weeks of academic year. Week $I=$ Sept. 12-18, 1988; week $10=$ Nov. $13-$ 19, 1988; week 25 = Feb. 27-March 6, 1989; week 40 = June 12-18, 1989; etc.

\section{$Y$ axis - number of public online catalog transactions, in thousands}

\section{FIGURE 1}

1988/89 Online Searches

high. As table 1 shows, fifty (17.2\%) of the titles circulated locally during the $1988 / 89$ academic year. The enhance group accounted for twenty-three ( $46 \%$ ) of these fifty circulating titles, compared to fourteen $(28 \%)$ for the control and thirteen $(26 \%)$ for the contents-notegroup titles.

These totals were unexpected, given previous studies which had not established a pattern of more use for books with more subject headings. However, the differences were measured by a chisquare test and found not to be statistically significant at the .05 level, despite the considerable variation. A value of 4.30 was obtained on the test, with 5.99 required for .05 significance at two degrees of freedom. Thus, the null hypothesis that circulation frequency is independent of variations in the catalog record was not disproved.

The chi-square test is suitable for data that can be put in one or another cell, as in whether or not a book has circulated, but not for variable data such as comparing multiple circulations of some of the books. Therefore, the remaining statistics are presented without this test.

Another measure of circulation, one which may be most telling regarding the possible effects of an enhanced catalog record, involves the number of separate circulations per title. A book checked out at two different times (thus excluding renewals) is likely a reflection of two distinct catalog searches. Once again the enhance group of books had the highest circulation rate with twenty-six separate local circulations ( $48.1 \%$ of this total), compared to fifteen $(27.8 \%)$ for the control and thirteen $(24.1 \%)$ for the contents note group.

This pattern of higher use continued when total local circulations, including renewals, were examined. Renewals do not reflect a reuse of the catalog, and are, therefore, less helpful for interpreting book use than are separate circulations; but they do give some measure of the 


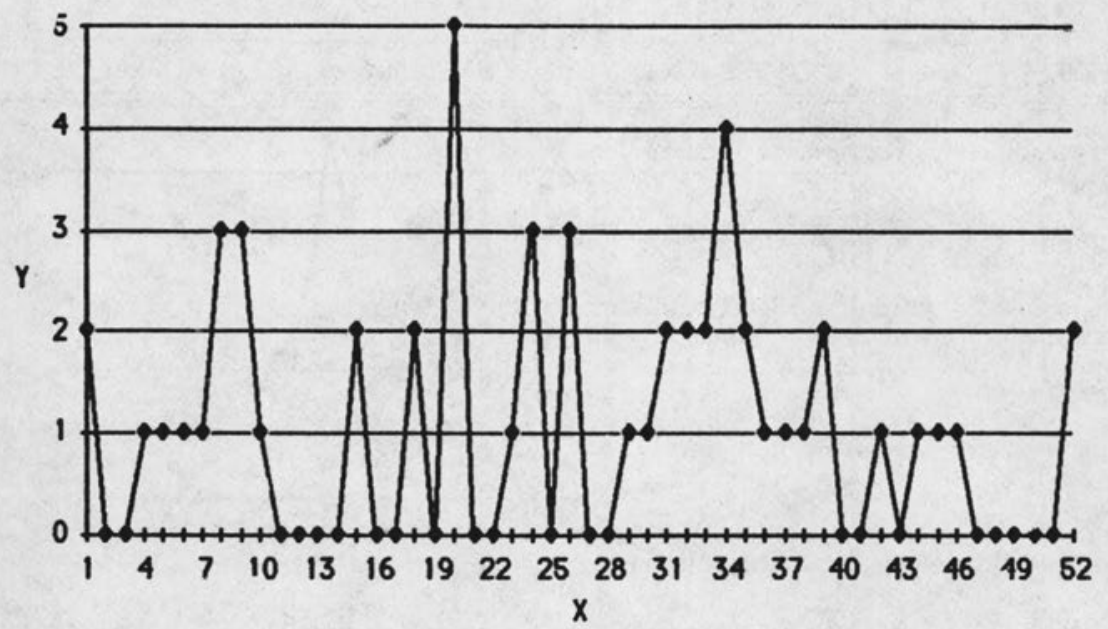

$X$ axis $=$ weeks of academic year. Week $1=$ Sept. 12-18, 1988; week $10=$ Nov. $13-$ 19, 1988; week 25 = Feb. 27-March 6, 1989; week 40 = June 12-18, 1989; etc.

\section{$Y$ axis = number of local circulations per week for books in the sample (renewals excluded)}

FIGURE 2

1988/89 Local Circulations of Experimental Group

relevance of books to the user. Renewals are often included in circulation studies as if they were the equivalent of other circulations. In the present study, the enhance group again had the highest total local circulation figures when renewals were added to the figures. Enhanced titles accounted for forty-six such circulations (52.3\%), compared to twenty-two $(25 \%)$ for the control and twenty $(22.7 \%)$ for the contents note group.

A final set of figures involves nonlocal circulation. This was the one area where the local catalog would be unlikely to affect choice of books, and it was the only area where the enhance group did not have the most additional circulations. The enhance group had four nonlocal circulations (including one renewal), the control group had one, and the contents group had five. After adding these non- local figures, the enhance group accounted for fifty total circulations (51\%), while the control group accounted for twenty-three $(23.5 \%)$ and the contents group for twenty-five (25.5\%).

The circulation statistics and the chisquare test results are inconclusive re-

The data all point towards the likelihood that the added subjects for the enhance group did influence circulation.

garding whether or not the addition of controlled subject headings leads to higher circulation. The data all point toward the likelihood that the added subjects for the enhance group did influence 
TABLE 1

SUMMARY OF USE OF EXPERIMENTAL GROUPS DURING 1988/89 ACADEMIC YEAR

\begin{tabular}{|c|c|c|c|c|}
\hline Group & Enhance & Control & Contents & Total \\
\hline \multicolumn{5}{|c|}{ 1. Titles circulating once or more (local circulations only) } \\
\hline $\mathrm{n}$ & 97 & 97 & $96^{*}$ & 290 \\
\hline $\mathrm{n}$ circs & 23 & 14 & 13 & 50 \\
\hline $\begin{array}{l}\% \text { of group } \\
\text { circs }\end{array}$ & $46 \%$ & $28 \%$ & $26 \%$ & $100 \%$ \\
\hline \multicolumn{5}{|c|}{$\begin{array}{l}\text { Chi-square: } 4.30 \text { (with } 2 \mathrm{df}, .05 \text { level significance requires } 5.99 \text { ) } \\
\text { 2. Separate local circulations per title, excluding renewals }\end{array}$} \\
\hline n circs & & 15 & & 54 \\
\hline $\begin{array}{l}\% \text { of group } \\
\text { circs }\end{array}$ & $48.1 \%$ & $27.8 \%$ & $24.1 \%$ & $100 \%$ \\
\hline \multicolumn{5}{|c|}{ 3. Total local circulations, including renewals } \\
\hline $\begin{array}{l}\text { n of group } \\
\% \text { of }\end{array}$ & $52.3 \%$ & $22 \%$ & $20.7 \%$ & $\begin{array}{c}88 \\
100 \%\end{array}$ \\
\hline \multicolumn{5}{|c|}{ 4. Nonlocal circulations, including renewals } \\
\hline $\begin{array}{l}\mathrm{n} \text { circs } \\
\% \text { of group } \\
\text { circs }\end{array}$ & $\begin{array}{c}4 \\
40 \%\end{array}$ & $10 \%$ & $50 \%$ & $\begin{array}{c}10 \\
100 \%\end{array}$ \\
\hline \multicolumn{5}{|c|}{ 5. Total circulations, including nonlocal and renewals } \\
\hline circs & 50 & 23 & & 98 \\
\hline $\begin{array}{l}\% \text { of group } \\
\text { circs }\end{array}$ & $51 \%$ & $23.5 \%$ & $25.5 \%$ & $100 \%$ \\
\hline
\end{tabular}

*One book missing

circulation, but, as seen above, the chisquare test on first-time local use per title did not show a statistically significant difference among the groups. The number of recorded uses was too small for an analysis of variance test of the data to be appropriate, but sufficient evidence was found to warrant future investigation on a larger scale.

Before drawing conclusions and making recommendations for further research, it remains to comment on some other possible influences on book use. Other factors which could have had an influence in this library settingbrowsing, keyword searching, and the OPAC display-can be measured to a degree.

\section{BROWSING AND CIRCULATION}

The three test groups were drawn from a homogeneous population. All were added to the collection during the same period, were similar in publication date, length, and number of LC subjects (before the enhancements), and were evenly distributed throughout the $\mathrm{H}$ classification. The fact that none had previously circulated eliminated a number of influences as likely causes of their use during this period, which left browsing as a prime consideration. How likely was it that users found the books by scanning the shelves rather than by searching the online catalog?

In some libraries, users may be so familiar with the collection that they can bypass the catalog and go directly to the shelves, where the display of titles can influence selection. Taylor found that at a medium-sized public library there is a significant relationship between eyelevel shelf position and book use, ${ }^{22}$ and S. L. Baker also reported that prime display location increases public library circulation. ${ }^{23}$ Herman Fussler and Julian L. Simon noted that even in a research collection, some book use may possibly be related to shelf position. ${ }^{24}$

In the test library, the social science collection was shelved in open stacks. There were an estimated 85- 90,000 titles plus many added volumes in the $\mathrm{H}$ classification. These occupied about twentysix double-faced stack ranges which were as long as forty feet, stood seven shelves high, and were separated by 
thirty-inch aisles. The bottom shelf was just three inches off the floor, with the other shelves positioned at about onefoot intervals. The top shelves were not at a uniform height but varied from about eighty to eighty-four inches off the floor.

The highest and lowest shelves were the least accessible to browsers. Shelves four through six (counting upwards) were at or near eye level for most users, and these books could be easily reached. Reaching shelves two and three required a deep knee bend, though a kneeling person could browse and reach easily.

Table 2 shows the number of books per shelf, the number of local circulations, and the percentage of items circulated. Highest circulation percentages are for levels two (not readily browsed) and six (easily browsed), followed by level three (not readily browsed), levels seven and four, etc. There is no clear pat- tern. The circulation rate is twice as high for level seven, which often requires use of a step-stool, than for the very accessible level five (which has lowest local use- $-7.5 \%$ ). Thus, it appears that shelf location was not a decisive factor in these circulation statistics.

A less obvious type of browsing involves the physical appearance of the book. Table 3 shows the local circulation breakdown by type of binding. About two-thirds of the books are in the original publisher's hardcover bindings, and these are nearly twice as likely to circulate as rebindings (i.e., former paperbacks). However, the enhance group has the fewest original bindings (fiftyeight, compared to sixty-five for the control and sixty-three for the contents group), and the circulation rate of rebound enhance books is actually slightly higher $(17.9 \%)$ than the rate for original bindings of the other groups $(16.9 \%$ and $17.5 \%)$. Thus, it is clear that the higher

TABLE 2

SHELF LEVEL AND LOCAL CIRCULATION

\begin{tabular}{lcrc}
\hline \hline Shelf & No. of Books & $\begin{array}{c}\text { Local Circ. } \\
\text { (no. and \%) }\end{array}$ & $\begin{array}{c}\text { Rank } \\
\text { (by Circ. \%) }\end{array}$ \\
\hline 7 (top) & 32 & $5(15.63)$ & 4 \\
6 & 49 & $12(24.49)$ & 2 \\
5 & 40 & $3(7.50)$ & 7 \\
4 & 45 & $7(15.56)$ & 5 \\
3 & 39 & $7(17.95)$ & 3 \\
2 & 53 & $13(24.53)$ & 1 \\
1 & 32 & $3(9.38)$ & 6 \\
\hline
\end{tabular}

TABLE 3

TYPE OF BINDING AND LOCAL CIRCULATION

\begin{tabular}{lcc}
\hline \hline Enhance & $\begin{array}{c}\text { Original } \\
\text { Binding }\end{array}$ & Rebound \\
\hline $\mathrm{N}$ & 58 & 39 \\
Local Circ. (n) & 16 & 7 \\
Local Circ. (\%) & 27.6 & 17.9 \\
Control & & 32 \\
$\mathrm{~N}$ & 65 & 3 \\
Local Circ. (n) & 11 & 9.4 \\
Local Circ. (\%) & 16.9 & 33 \\
Contents & & 2 \\
$\mathrm{~N}$ & 63 & 6.1 \\
Local Circ. (n) & 11 & 104 \\
Local Circ. (\%) & 17.5 & 12 \\
Total & 186 & 11.5 \\
$\mathrm{~N}$ & 38 & \\
Local Circ. (n) & 20.4 & \\
Local Circ. (\%) & & \\
\hline & &
\end{tabular}


use for books with added subjects was not the incidental effect of their having a preferred binding. And it appears that browsing-as defined by shelf position and physical appearance of books-was not a deciding factor in circulation at this research library.

\section{OBSERVATIONS ON KEYWORD SEARCHING}

Keyword searching is a major advantage of an online catalog. It frees a user from the restrictions of controlled subject vocabulary and permits serendipity to play a role in access. This has led to considerable speculation on the possibility of improving subject access by making catalog records more amenable to keyword searching. Markey and Calhoun have shown that contents notes are a major source of unique terms in MARC records and are one of the most practical ways to add subject-rich terminology to catalog records. ${ }^{25}$

The presence of an easy-to-use keyword capability combined with added subject terminology from contents notes may improve retrieval potential.

Because keyword searches may serve as substitutes for unsuccessful controlled subject searches, adding a contents note as well as additional LC subject headings can lead to confusion over which factor predominates in bibliographic retrieval. For this reason, a third category was added to the experimenta group of records with no added subjects but with a full contents note. If both the enhance and contents note groups had equally high circulation compared to the control group, it might be assumed that either keyword searching or the additional information present for the user in the online display was a key factor influencing choice of books. If the contents group had fewer circulations than the enhance group, but more than the control group, it also might be as- sumed that the notes themselves were having a positive effect, but that the additional subjects were a further positive factor.

As seen from table 1, the contents note group in fact had the lowest local circulation by all three measures. This was a small difference from the control group, but, because these records presented more information to the user, the result was unexpected and indicated a need for further investigation of keyword searching on the public catalog.

The NOTIS-based local online catalog is an easy system for users to learn. Commands are few and straightforward, and automatic right truncation of search terms means that the user need not enter a full heading to receive a response. Keyword is more challenging, but it was routinely introduced during quarterly catalog demonstrations and also featured on the introductory help screens. Keyword was available on the local online catalog for the first forty-five weeks of the experiment, then temporarily suspended because of installation of NOTIS 4.6. During these forty-five weeks the public catalog averaged 79,100 transactions per week; of these, an average of just $2.04 \%$ were keyword. Although figures were not available for other types of searches, the highest weekly figure for keyword searches was 2,799 out of a total of 118,230 public catalog transactions.

Because keyword had also been available prior to the experiment, the author returned to the full data for 1986 additions in the social sciences. Seven hundred ninety-three titles identified as collections of essays and conference papers had been added that year. As of the summer of 1988,502 had circulated at least once and 291 had not. But only a small minority $(7.2 \%)$ had contents notes. The number of contents notes on collections having circulated was only twenty-three $(4.6 \%)$, while for the uncirculated group it was thirty-four (11.7\%). A chi-square test gave a value of 13.93 , which showed this difference to be significant at the .001 level.

These figures are puzzling. Because most of the cataloging was done by LC, 
and LC apparently added contents notes sparingly at this time, it might be that books with these notes represent qualitatively different material. The alternative-that users are more likely to reject a book than to select it based on a reading of the contents note-does not explain why they would not do the same thing for the enhance group. At any rate, it appears that the presence of an easy-to-use keyword capability combined with the added subject terminology from contents notes may improve retrieval potential, but does not, by itself, assure that books will have a higher use rate.

\section{OPAC DISPLAY}

According to the three measures of local circulation, the major factor contributing to increased use appeared to be the additional subject headings which made these works more accessible to users. This must be viewed within the context of the OPAC display.

NOTIS 4.5 subject searches display data in newest-first order. In most cases, the user first sees a guide screen with all matching subject terms. The user requests a particular subject or subjectsubdivision combination and next retrieves an index screen with one-line title entries in reverse chronological order. From this point one may choose to see the full record for a title. Relatively new works appear on the first index screen unless there are a very large number of new titles. A title with a subject subdivided to a more specific level becomes even more likely to display prominently.

Because the books in this experiment were mostly new, with a mean publication date of 1985, most of their subjects would have appeared near the top of index screens during the $1988 / 89$ academic year. Some of these subjects were also unique and would be the lone response to a request for a line on the guide screens. (Dwyer has observed that "very specific subject headings are particularly useful in online catalogs with large databases." ${ }^{26}$ ) Thus it seems that both the additional subjects, plus their favorable online display position, com- bined to make it more likely that users would choose the enhanced titles. One cannot assume that a similar addition of subjects to a card catalog, or to an OPAC which displayed them in alphabetical rather than reverse chronological order, would have the same effect. However, if this explanation accounts for the observed higher local use, it also may indicate a general method of increasing book use in large research collections. Providing more subject information, and making its display prominent to the catalog user, appears to be a successful combination for promoting the use of newer books.

\section{DISCUSSION AND CONCLUSIONS}

The problems of subject access and book use in a research library become increasingly complex when an effort is made to link the two, yet without making this link a library may not receive the full promise of catalog improvements. An assumption of subject enhancement theory is that patrons will benefit by finding and using more books, or different books, than they would have found previously. This experiment tested one method of increased subject access and found some indications of such benefit.

The project was designed to test whether adding a substantial number of controlled subject headings would have a positive impact on book use-an effect that was not observed in previous studies that tried to correlate circulation with the number of subjects or access points on existing catalog records. Despite the fact that the variation in circulation of the titles fell short of the .05 level of significance in a chi-square test, the findings offer encouragement for future testing in this area. By three different measures of local circulation, the subject-enhanced records accounted for about half of all use even though they represented only a third of the books. These figures indicate that use might be increased to a statistically significant level through further subject additions.

These findings raise the question of whether circulation rates for research library materials may be improved through catalog enhancements. While it 
is clear that many books are simply too specialized to be used often, it appears that a substantial increase in the level of subject indexing may have a positive effect on use in specific areas-in this case, essay and conference paper compilations. Further testing in other library settings is needed to see whether similar or better results can be obtained and to determine whether such use is high enough to justify added cataloging costs.

One generalization is that precoordinate subject indexing still has an important role to play in the era of online catalogs. Although the evidence gathered here was mixed and should be viewed with caution, the enhance group had consistently higher local circulation than the other groups. While previous studies have found no correlation between number of subjects and frequency of circulation, this is probably because there is little relative difference in subject depth between books in standard cataloging. Adding a substantial number of subjects in order to bring out more of the content is a different approach to cataloging.

If the added subjects truly led to more use, the online subject display must have been a contributing factor. This newestfirst display is an effective way of bringing such titles to the attention of users and should be given close consideration in catalog design. In a large research library users may prefer to brow $-e$ the online catalog rather than browsing the shelves, but only if it is easy to find the type of materials they are seeking. In a subject search, these materials are often the newest works on a topic.

Adding contents notes to catalog records is a convenient method of increasing the number of terms available for keyword searching, but such records were not associated with higher circulation rates in this experiment, possibly because patrons used keyword searching relatively infrequently. The fact that a search capability is easy to use apparently does not guarantee that it will be used often, or efficiently, by patrons accustomed to the usual author, title, and subject searches. An interesting extension of this research would be for a li- brary to place a major emphasis on promoting keyword searching, then observe whether little-used books began to circulate more frequently.

Browsing, defined as ease of viewing and reaching books on different shelf levels, did not have any consistent effect on book selection. Type of binding had a positive overall association with book circulation, with users preferring original bindings. However, when analyzed further, type of binding proved not to be the cause of higher enhance group use.

Although encouraging, these results are not an unqualified endorsement of controlled subject vocabulary as the best or only means of enhancing catalog records. The process is very time consuming, and adequate terminology is not always available in LCSH for describing an essay-level subject. More important than the particular method used, however, was the indication that an increase in subject-access terms available for searching may indeed be a key to higher book use.

In addition to increasing the number of LC subjects on new cataloging, the search process itself could be modified. Concepts such as the "Superthesaurus" described by Marcia J. Bates, ${ }^{27}$ designed to channel a wide variety of search terms to the controlled vocabulary actually in use, would increase the likelihood of a user arriving at one of the assigned subject terms. The effects of a "Superthesaurus" for the user might be similar to the labor-intensive addition of more LC subjects, particularly for those general works which are more difficult to enhance than are collections of essays. The online catalog display is also clearly important. New subjects are less likely to affect use if they are not linked to titles which appear prominently in an online index. It would be helpful to test various approaches in actual library settings to see how they perform compared to the traditional catalog.

In conclusion, the experiment produced mixed results. The data suggested that greater subject access may actually have an effect on circulation patterns in research collections, though the statistical test employed did not rule out chance error as a possibility. However, 
the project did provide a methodology for testing the practical effects of subject enhancement, and the results were more encouraging than earlier research in that there was a definite pattern of more use for enhanced materials.
Further study along these lines is certainly called for as a result of this experiment. The problem of providing better subject access for research collections remains one of the greatest challenges and opportunities for catalogers in the 1990s.

\section{REFERENCES}

1. Edward T. O'Neill and Rao Aluri, "Library of Congress Subject Heading Patterns in OCLC Monographic Records," Library Resources \& Technical Services 25:63-80 (Jan./Mar. 1981).

2. James R. Dwyer, "The Road to Access \& the Road to Entropy," Library Journal 112:131-36 (Sept. 1, 1987).

3. Allen Kent and others, Use of Library Materials: The University of Pittsburgh Study (New York: Dekker, 1979).

4. Ibid., p. 200.

5. Pauline Atherton, Books Are for Use: Final Report of the Subject Access Project to the Council on Library Resources (Syracuse, N.Y.: Syracuse University, School of Information Studies, 1978), p.88.

6. Alex Byrne and Mary Micco, "Improving OPAC Subject Access: The ADFA Experiment," College \& Research Libraries 49:432-41 (Sept. 1988).

7. William Aguilar, "Influence of the Card Catalog on Circulation in a Small Public Library," Library Resources \& Technical Services 28:175-84 (April/June 1984).

8. Margaret Ann Thomas Taylor, "The Effect of Bibliographic Accessibility upon Physical Accessibility in a Public Library Setting," (Ph.D. diss., University of Michigan, 1982), p. 90.

9. Pal V. Rao, "The Relationship between Card Catalog Access Points and the Recorded Use of Education Books in a University Library," College \& Research Libraries 43:341-45 (July 1982).

10. Gunnar Knutson, "Does the Catalog Record Make a Difference? Access Points and Book Use," College \& Research Libraries 47:460-69 (Sept. 1986).

11. Carol A. Mandel and Judith Herschman, "Online Subject Access-Enhancing the Library Catalog," Journal of Academic Librarianship 9:148-55 (July 1983).

12. Knutson, "Does the Catalog Record Make a Difference?" p.468.

13. William Carl Highfill, "The Relationship of Indexing Depth to Subject Catalog Retrieval Effectiveness" (Ph.D. diss., University of Illinois at Urbana-Champaign, 1969), p.233.

14. Ibid.

15. Carol A. Mandel, "Enriching the Library Catalog Record for Subject Access," Library Resources \& Technical Services 29:5-15 (Jan.-Mar. 1985).

16. Ibid., p.14.

17. Karen Markey and Karen Calhoun, "Unique Words Contributed by MARC Records with Summary and/or Contents Notes," in ASIS '87: Proceedings of the 50th ASIS Annual Meeting (Medford, N.J.: Learned Information, 1987), p.153-62.

18. Martin Dillon and Patrick Wenzel, "Enhanced Bibliographic Record Retrieval Experiments," OCLC Newsletter 181:13-14 (Sept./Oct. 1989).

19. Mandel, "Enriching the Library Catalog Record," p.13.

20. Larry Hardesty, "Use of Library Materials at a Small Liberal Arts College: A Replication," Collection Management 10:61-80 (1988).

21. Kent et al., Use of Library Materials, p.15.

22. Taylor, "Effect of Bibliographic Accessibility," p.123.

23. S. L. Baker, "The Display Phenomenon: An Exploration into Factors Causing the Increased Circulation of Displayed Books," Library Quarterly 56:237-57 (1986).

24. Herman Fussler and Julian L. Simon, Patterns in the Use of Books in Large Research Libraries (Chicago: University of Chicago Pr., 1969), p.115.

25. Markey and Calhoun, "Unique Words," p.160.

26. Dwyer, "Road to Access," p.132.

27. Marcia J. Bates, "Rethinking Subject Cataloging in the Online Environment," Library Resources \& Technical Services 33:400-12 (Oct. 1989). 